\title{
Kebiasaan Makan Ikan Seluang (Rasbora argyrotaenia) di Perairan Sungai Musi
}

\author{
Helmi Haris $^{1 *}$, Dian Mutiara ${ }^{2}$, N. Arsyad ${ }^{3}$ \\ e-mail: helmiharris76@yahoo.com \\ ${ }^{1}$ Program Studi Ilmu Perikanan, Fakultas Perikanan, \\ ${ }^{2}$ Program Studi Biologi Fakultas MIPA \\ Universitas PGRI Palembang \\ ${ }^{3}$ Pemerhati Perikanan
}

\begin{abstract}
Seluang (Rasbora argyrotaenia) is one type of fish that lives on the Musi River in South Sumatra. Seluang is favored by the people of South Sumatra to become consumption fish with economic value. Natural catches are felt to diminish over time and effort is needed for domestication and cultivation. Analysis of gastric contents has been carried out on seluang fish from the Musi river to find out fish eating habits as a cultivation platform. The research was conducted from July to September 2017 on three Musi tributaries. The Prefonderance index was analyzed according to Natarjan and Jhingran in Effendi (2002). From the results of the study it was revealed that eluang was an omnivorous group of fish seen from the value of the Prefonderance Index, which consumed green plants (48.05\%) as the main food, Arthropoda (23.86\%) and Anellida $(22.35 \%)$ as supplementary foods.
\end{abstract}

Keywords: Musi River. Index of Prefonderance, Domestication, Omnivore

\begin{abstract}
ABSTRAK
Seluang (Rasbora argyrotaenia) merupakan salah satu jenis ikan yang hidup di sungai Musi Sumatera Selatan. Seluang disukai masyarakat Sumatera Selatan hingga menjadi ikan konsumsi yang bernilai ekonomi. Hasil tangkapan alam dirasakan semakin berkurang seiring waktu dan diperlukan usaha untuk domestikasi.dan budidaya. Analisis isi lambung telah dilakukan terhadap ikan seluang dari sungai Musi untuk mengetahui kebiasaan makan ikan sebagai landasan budidaya. Penelitian dilakukan pada bulan Juli sampai September 2017 pada tiga anak sungai Musi. Indek Prefonderance dianalisis menurut Natarjan dan Jhingran dalam Effendi (2002). Dari hasil penelitian diketahui bahwa Seluang merupakan kelompok ikan omnivora yang dilihat dari nilai Indek Prefonderance yaitu mengkonsumsi tumbuhan hijau $(48,05 \%)$ sebagai makanan utama, Arthropoda $(23,86 \%)$ dan Anellida $(22,35 \%)$ sebagai makanan tambahan.
\end{abstract}

Kata Kunci: Sungai Musi. Indek of Prefonderance, Domestikasi, Omnivora

\section{PENDAHULUAN}

Ikan seluang (Rasbora argyrotaenia) adalah salah satu spesies ikan yang terdapat pada sungai Musi Sumatera Selatan. Ikan ini tersebar di wilayah Sumatera sampai Kalimantan dan beberapa perairan di Indonesia. Aryani (2015) mendapatkan spesies Rasbora argyrotaenia di sungai Kampar Kanan provinsi Riau. Yustina (2001) Rasbora argyrotaenia juga terdapat di perairan 
sungai Rengau provinsi Riau. Lisna (2013) telah mengoleksi Rasbora argyrotaenia dari sungai Kumpeh Muaro Jambi. Rosadi (2014) juga mendapatkan seluang di sungai Barito Kalimantan Selatan. Ikan seluang juga diketahui hidup di sungai Rungan Kalimantan Tengah, (Sulistiyarto 2012).

Di Palembang ikan seluang sangat disukai dan bernilai ekonomis tinggi. Hasil tangkapan alam dirasakan tidak mencukupi untuk kebutuhan masyarakat hingga diperlukan usaha budidaya. Langkah utama untuk budidaya adalah mengetahui kebiasaan makan atau pakan alami ikan seluang pada habitatnya. Seluang membutuhkan pakan alami spesifik untuk pertumbuhan dan perkembangannya. Husnah dan Nasyirudin (2009) menjelaskan bahwa ikan Seluang termasuk kelompok omnivora yang mengkomsumsi makanan yang berasal dari hewan dan tumbuhan seperti fitoplankton maupun zooplankton.

Keanekaragaman ekologi, topografi dan habitat yang terdapat di aliran anak Sungai Musi $\mathrm{Pa}$ l e m b a n g Sumatera Selat an memungkinkan adanya jenis pakan alami yang berbeda pada ikan Seluang. Selain itu, bervariatifnya dugaan tentang jenis pakan alami ikan Seluang mendorong peneliti untuk mengkaji lebih lanjut mengenai keanekaragaman pakan alami yang terdapat dalam lambung ikan Seluang karena hal ini mendasari domestikasi ikan seluang dari sungai Musi. Dengan pengamatan isi lambung maka kebiasaan makan (Feeding Habit) ikan Seluang di aliran anak sungai Musi dapat diketahui. Menurut Dwitasari $d k k$ (2016).. Kajian isi lambung perlu dilakukan sebelum proses domestikasi. Diharapkan penelitian ini akan memberikan kontribusi informasi kepada masyarakat tentang isi lambung ikan Seluang juga alternatif pengembangan budidaya untuk pakan alami ikan Seluang di masa datang.

\section{BAHAN DAN METODOLOGI}

Penelitian dilaksanakan pada bulan Juli sampai September 2017 bertempat di tiga lokasi perairan Sungai Musi, sedangkan pengamatan isi lambung dilakukan di Balai Penelitian Perikanan Perairan Umum (BPPPU) Palembang. Alat yang digunakan adalah bok sample , Tangkul, Mikroskop, Ember volume 5 liter , caliper, $\mathrm{pH}$ meter, Thermometer , Camera dan alat tulis. Bahan yang digunakan ikan seluang dan formalin $4 \%$. Penangkapan ikan pada tiga lokasi dilakukan dengan tangkul supaya ikan yang didapat tidak cacat dan tidak terlalu stress yang dilakukan pagi hari pukul 07.00 WIB. Ikan yang didapat langsung diukur berat dan panjangnya. Tiap lokasi diambil sebanyak 10 ekor hingga keseluruhan sampel sebanyak 30 ikan dengan ukuran berkisar $\pm 10 \mathrm{~cm}$ hingga $\pm 13 \mathrm{~cm}$. Selanjutnya ikan dibedah dan diambil lambungnya. kemudian, masingmasing lambung ikan tersebut dimasukkan ke dalam 30 botol filum plastik berisi formalin $4 \%$. dan dimasukan dalam Box. Lambung ikan dianalisis di Laboratorium Balai Penelitian Perikanan Perairan Umum (BPPPU) berdasarkan analisis Index of Preponderance atau Indeks Bagian Terbesar menurut Natarjan dan Jhingran dalam Effendi (2002) :

$$
\mathrm{IP}=\frac{\mathrm{Vi} \times \mathrm{Oi}}{\sum \mathrm{Vi} \times \mathrm{Oi}} \times 100 \%
$$

Dimana :

IP : Index of Preponderance atau Indeks Bagian Terbesar (\%) V Persentase volume satu jenis makanan Oi : Persentase frekuensi kejadian satu jenis makanan $\Sigma$ VixOi : Jumlah Vi x Oi dari semua jenis makanan 
Jika nilai IP > 25\% dikatagorikan sebagai makanan utama, nilai IP 4- 25\% dikatagorikan sebagai makanan pelengkap, dan nilai IP $<4 \%$ sebagai makanan tambahan.

\section{HASIL DAN PEMBAHASAN}



Gambar 1. Lokasi pengambilan sampel Seluang di Aliran Sungai Musi

Dari peta lokasi dapat dilihat 3 lokasi pengambilan sampel yaitu : lokasi I Anak Sungai Musi di Desa Kenten Laut Kec. Talang Kelapa, dengan koordinat (2053'38.4”S 104046'42.0”E). Lokasi 2 Anak Sungai Musi di Kelurahan Pulo Kerto Kec. Gandus dengan kordinat (3001'44.6”'S 104039'39.7'E) sedangkan lokasi 3 Aliran Anak Sungai Musi di Desa Tanpa Nama Kecamatan. Mariana dengan koordinat (2057'32.0'S 104051'49.9'E). Secara umum keadaan masing-masing lokasi berbeda pada lokasi 1 merupakan sungai alami, lokasi 2 terdapat keramba sedangkan lokasi 3 terdapat aktivitas dan pemukiman penduduk dengan kecepatan arus yang sedang. Menurut Husna dan Nasyirudin (2009) ikan seluang dapat hidup pada tipe habitat mengalir seperti badan utama dan anak-anak sungai. Rentang kecepatan arus yang cukup luas pada bagian hulu, tengah dan hilir sungai masing-masing pada kisaran 4,4 - 16,7 $\mathrm{m} /$ detik, $0,2-1,1 \mathrm{~m} /$ detik, dan $0-1,0$ $\mathrm{m} /$ detik. Namun demikian, kecepatan arus yang disenangi adalah pada kisaran 0,2 $1,1 \mathrm{~m} /$ detik.
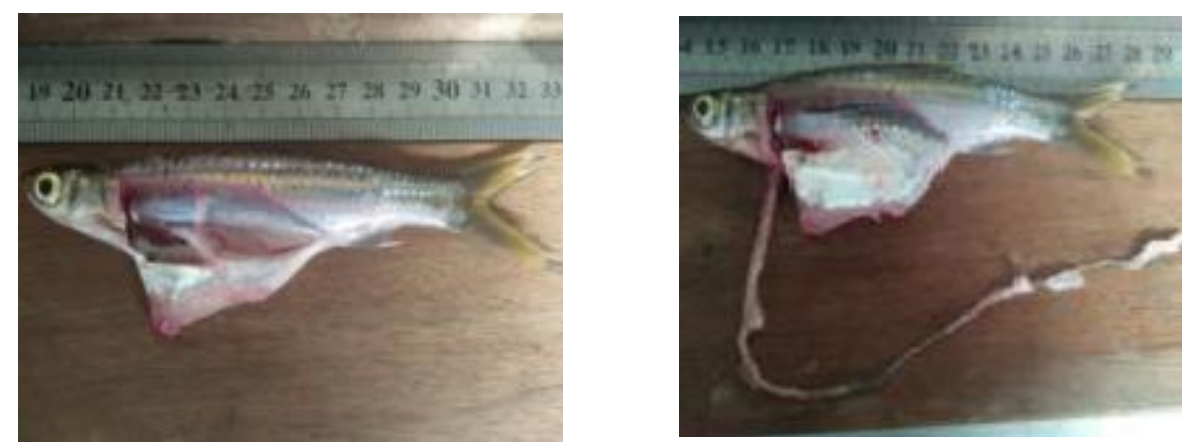

Gambar 2. Lambung dan usus Ikan Seluang

(Sumber: Dokumen Pribadi, 2017)

Lambung merupakan tempat bermuara dari makanan setelah dilakukan pencernaan di mulut dan tenggorokan. Menurut Effendie (2002), pengamatan 
isi lambung bertujuan untuk mendapatkan gambaran baku dari makanan yang dikonsumsi oleh ikan. Berdasarkan pengamatan bentuk lambung ikan seluang bulat memanjang seperti kantong dengan usus yang juga memanjang . Usus ikan Seluang memiliki panjang sekitar satu setengah panjang badan seperti terlihat pada gambar 2.

Jika dilihat dari perbandingan panjang usus dengan panjang badan ikan seluang termasuk jenis ikan omnivora. Menurut Zuliani $d k k$ (2016), kebiasaaan makanan ikan dapat juga diprediksi dari perbandingan panjang saluran pencernaannya dengan panjang total tubuhnya. Ditambahkan Syahputra $d k k$, (2014) katagori sifat makanan ikan tergantung dari perbandingan relatif panjang usus dengan badan yaitu ikan karnivora 1, omnivora 1-3 dan herbivor $>3$. Ikan seluang yang ditemukan memiliki rata-rata panjang usus berbanding dengan badan 1-3 dan dapat dikatagorikan ikan seluang termasuk ikan omnivora.

Tabel 1. Nilai Indek Prefonderance ikan seluang yang didapatkan pada sungai Musi.

\begin{tabular}{|c|c|c|c|c|c|}
\hline NO. & KELOMPOK & \multicolumn{3}{|c|}{ LOKASI } & RATA- \\
\hline & & $\begin{array}{c}\text { Sungai Musi } \\
\text { Desa Kenten } \\
\text { Laut }\end{array}$ & $\begin{array}{c}\text { Sungai Musi } \\
\text { Kelurahan } \\
\text { Purwokerto }\end{array}$ & $\begin{array}{c}\text { Sungai Musi } \\
\text { Desa Tanpa } \\
\text { Nama Mariana }\end{array}$ & \\
\hline & & \multicolumn{4}{|c|}{ INDEK of PREPONDERANCE $(\%)$} \\
\hline 1. & $\begin{array}{l}\text { Spermatophyta/Thal } \\
\text { ophyta }\end{array}$ & 48.27 & 45.43 & 50.45 & 48.05 \\
\hline 2. & Arthropoda & 24,21 & 24.39 & 22.99 & 23.86 \\
\hline 3. & Anellida & 23.09 & 23.33 & 20.64 & 22.35 \\
\hline 4. & Tercerna & 3.30 & 3.10 & 3.18 & 3.19 \\
\hline
\end{tabular}

Dari Tabel 1 di atas dapat diketahui perbedaan jenis pakan ikan seluang yang didapatkan pada tiga lokasi sampel. Kelompok pakan utama yang ditemukan pada tiap lokasi cenderung sama hal ini dikarenakan habitat ikan yang hampir sama. Ikan seluang diketahui mengkonsumsi bahan tumbuhan yang sama yang berasal dari kelompok Spermatophyta dan ganggang yang hidup di perairan sungai Musi . Secara ekologi bila lingkungan sekitar tempat hewan itu berada sama, maka kemungkinan besar memiliki kesamaan komponen penyusun baik hewan dan tumbuhan,Selain faktor fisik seperti sungai yang mengalir. Menurut Sulistiyarto (2012), diketahui 7 jenis bahan makanan yang terdapat dalam lambung ikan seluang yang ditemukan di sungai Rungan yaitu alga sel tunggal, alga filament, tumbuhan darat (daun,buah dan biji), detritus, rotifer, crustaceae renik dan insekta darat.

Pada pengamatan isi lambung ikan seluang pada tiga lokasi cenderung sama. Isi lambung ikan pada tiga lokasi ditemukan sisa tumbuhan sebagai makanan terbesar dengan nilai IP rata-rata $48,05 \%$. Adanya sisa tumbuhan ditemukan serpihan tumbuhan yang tidak utuh lagi tetapi masih terlihat ciri utama tumbuhan yang berklorofil dan serpihan tumbuhan rendah yang diduga adalah tumbuhan berthalus dicirikan adanya sisa tumbuhan yang berbentuk lembaran lembaran thalus. Berdasarkan nilai IP terbesar diketahui bahwa ikan seluang 
mengkonsumsi tumbuhan hijau sebagai makanan utamanya.

Berdasarkan perhitungan Indek of Prefonderance makanan pelengkap ikan seluang pada tiga lokasi adalah kelompok Arthropoda 23.86\% dan Anellida sebesar $22.35 \%$. Sisa Arthropoda yang ditemukan berupa potongan-potongan seperti tungkai dan antena serangga kecil yang bersegmen. Juga ditemukan setae serangga yang masih menempel pada kulit yang hampir tercerna. Diprerkirakan sisa organ serangga yang ditemukan berasal dari serangga air dan semut, laba-lana kecil serta larva Crustaceae seperti larva kepiting dan udang. Selain itu juga ditemukan Anellida yang berupa serpihan serpihan cacing yang dicirikan dengan potongan organ lunak memanjang tapi tidak bersegmen yang diduga potongan tubuh cacing air seperti Tubifex sp. Menurut Fitrinawati (2004) dalam Nurhidayah (2016) bahwa ikan dapat memanfaatkan kelompok makanan yang tersedia secara merata dalam jumlah yang banyak (generalis) dan mempunyai kemampuan menyesuaikan diri terhadap ketersedian makanan, sehingga daya adaptasi ikan tinggi terhadap kebiasaan makanannya serta dalam memanfaatkan makanan yang tersedia.

\section{KESIMPULAN}

Dari penelitian yang telah dilakukan ikan seluang Rasbora argyrotaenia di sungai Musi merupakan kelompok ikan omnivora yang dilihat dari nilai Indexs Prefonderance. Ikan seluang mengkonsumsi tumbuhan hijau (48,05\%) sebagai makanan utama, Arthropoda $(23,86 \%)$ dan Anellida (22,35 \%) sebagai makanan tambahan.

\section{Ucapan Terimakasih}

Pada kesempatan ini Penulis mengucapkan Terima kasih kepada Universitas PGRI Palembang yang telah memberikan kepercayaan kepada Tim Peneliti untuk melaksanakan penelitian ini. Tak lupa ucapan yang sama kepada DRPM DIKTI yang telah memberikan dana penelitian melalui Kontrak Penelitian Nomor: 621/SP2H/K2/KM/2017 Tanggal 20 Juni 2017.

\section{DAFTAR PUSTAKA}

Aryani. N. (2015). Native Species in Kampar Kanan River, Riau Province Indonesia. International Journal of Fisheries and Aquatic Studies, 2(5): 213-217

Dwitasari, P. P., Hasani, Q., \& Diantari, R. (2017). Kajian Isi Lambung Dan Pertumbuhan Ikan Lais (Cryptopterus Lais) Di Way Kiri, Tulang Bawang Barat, Lampung. $e$ Jurnal Rekayasa dan Teknologi Budidaya Perairan, 5(2), 611-620.

Effendie, M. I. (1997). Biologi perikanan. Yayasan Pustaka Nusatama. Yogyakarta, 163.

Nurhidayah.F. Moh. Mustakim dan S. Alexander Samson (2016). Studi Kebiasaan Makanan Ikan Belida (Notopterus Notopterus) di Perairan Mahakam Tengah (Danau Semayang dan Danau Melintang) Kabupaten Kutai Kartanegara. Jurnal Ilmu Perikanan Tropis, 22(1)

Husnah dan N.M. Arsyad. (2009). Keragaman Jenis Seluang (Rasbora sp.) di Perairan Umum. Universitas PGRI Palembang Bekerjasama dengan Balai Riset Perikanan Perairan Umum Palembang. Palembang. 56 hal

Lisna. (2013). Seksualitas, Nisbah Kelamin dan Hubungan PanjangBerat (Rasbora Argyrotaenia) Di 
Sungai Kumpeh Kabupaten Muaro Jambi. Jurnal Penelitian Universitas Jambi Seri Sains, 15(2): 7-14.

Rosadi, E., Setyohadi, D., \& Bintoro, G. (2014). Distribution, Composition, and Abiotic Environment of Silver Rasbora (Rasbora argyrotaenia Blkr) Fish in Upstream Areas of Barito Watershed, South Kalimantan. Journal of Environment and Ecology, 5(1), 117-131.

Sulistiyarto, B. (2012). Hubungan panjang berat, faktor kondisi, dan komposisi makanan ikan Saluang (Rasbora argyrotaenia Blkr) di dataran banjir sungai Rungan, Kalimantan Tengah. JURNAL ILMU HEWANI TROPIKA (JOURNAL OF TROPICAL ANIMAL SCIENCE), 1(2), 62-66.
Syahputra, H., Bakti, D., \& Kurnia, M. R. (2014). STUDI KOMPOSISI MAKANAN IKAN SEPAT RAWA (Trichogaster trichopterus Pallas) di RAWA TERGENANG DESA MARINDAL KECAMATAN PATUMBAK. Aquacoastmarine, 5 (4); 60-71.

Yustina (2013). Keanekaragaman Jenis Ikan Di Sepanjang Perairan Sungai Rangau, Riau Sumatra. Jurnal Natur Indonesia , 4(1): 1-14

Zuliani.Z. Zainal A. Muchlisin, Nurfadillah Nurfadillah. (2016). Kebiasaan Makanan dan Hubungan Panjang Berat Ikan Julung -Julung (Dermogenys Sp.) di Sungai Alur Hitam Kecamatan Bendahara Kabupaten Aceh Tamiang. Jurnal Ilmiah Mahasiswa Kelautan dan Perikanan Unsyiah, 1(1): 12-24 